\title{
Importance of genetic testing in neonatal diabetes and use of sulphonylurea
}

\author{
Eman Ahmad Alsafi ${ }^{1}$, Ihab Abdulhamed Ahmad ${ }^{1,2}$, Abdulmoein Eid AL-Agha ${ }^{1}$ \\ ${ }^{1}$ Department of Pediatrics, Elsafi, Al-Agha and Ahmad, King Abdulaziz University Hospital, Jeddah, Kingdom of Saudi Arabia \\ ${ }^{2}$ Department of Pediatrics, Ahmad, Zagazig university Hospital, Egypte
}

Email address:

aagha@kau.edu.sa (A. E.AL-Agha), ihabhalaby2002@hotmail.com (I. A. Ahmad), e.alsafi@msn.com (E. A. Alsafi)

\section{To cite this article:}

Eman Ahmad Alsafi, Ihab Abdulhamed Ahmad, Abdulmoein Eid AL-Agha. Importance of Genetic Testing in Neonatal Diabetes and Use of Sulphonylurea. American Journal of Biomedical and Life Sciences. Vol. 3, No. 4, 2015, pp. 84-86. doi: 10.11648/j.ajbls.20150304.13

\begin{abstract}
Patients with permanent neonatal diabetes usually present within the first three months of life and need insulin treatment. In most, the cause is unknown. Because ATP-sensitive potassium (KATP) channels mediate glucose-stimulated insulin secretion from the pancreatic beta cells, activating mutations in the gene encoding the Kir6.2 subunit of this channel (KCNJ11) cause neonatal diabetes. Genotyping identifies the exact molecular etiology of early onset insulin requiring diabetes and has the potential to alter the management of the patient, who would otherwise be insulin dependent for life. Method: We identified a 6 year-old child who presented at 3 months of age with diabetic ketoacidosis. Blood samples for molecular genetic analysis were done. Results: The patient was diagnosed as a heterozygous for a missense mutation in the (KCNJ11) gene, for which she switched to sulphonylurea with a dose of $0.05 \mathrm{mg} / \mathrm{kg} / \mathrm{day}$. Conclusion: the need for medical practitioners to consider molecular testing for all patients who present with diabetes below 6 months of age as this will facilitate accurate diagnosis and appropriate therapy.
\end{abstract}

Keywords: Genetic Analysis, Neonatal Diabetes, Sulphonylurea

\section{Introduction}

Neonatal diabetes defined as persistent hyperglycemia occurring in the first months of life that lasts more than two weeks and requires insulin for management, which is a rare cause of hyperglycemia. The estimated incidence is one in 500,000 birth (1). The most common cause of permanent neonatal diabetes is due to activating mutations in the KCNJ11 gene, which encodes Kir6.2 (2,3). Oral sulfonylurea therapy appears to be more effective than the insulin in controlling hyperglycemia $(4,5)$.

We are presenting a case of 6 year-old female child who was diagnosed with neonatal diabetes at the age of three months and immediately started on insulin treatment. At age of 6 years, Genetic testing confirms mutation in the KCNJ11 gene for which she switched to sulphonylurea with a dose of $0.05 \mathrm{mg} / \mathrm{kg} / \mathrm{day}$.

\section{Case History}

This 6 year-old, girl who had previously been considered to have neonatal diabetes. She was diagnosed with diabetes at the age of three months and treated with insulin thereafter. She was born at 40 weeks' gestation by normal delivery, with a birth weight of 2.6 kilogram. Neither of her parents nor any other family members have type 1 diabetes. Recently her father diagnosed with diabetes at age of 35 years old.

She was presented with history of polyuria and irritability which was associated weight loss. This was complicated by sever diabetic ketoacidosis needed pediatric intensive care admission admission. (remove )

Her early treatment involved twice-daily intermediate insulin; however, at the age of 6 years her total insulin dose reach 0.5 units $/ \mathrm{kg}$ with good glycemic control $\left(\mathrm{HbA}_{1 \mathrm{c}}\right.$ level range $5.5-7.14 \%$ [99 - $128.5 \mathrm{mmol} / \mathrm{mol}]$ ) with no history of remission.

She was regularly following up with the pediatric endocrine clinic. Her blood glucose levels were ranging from $70-250 \mathrm{mg} / \mathrm{dl}$. Never been admitted to the hospital with any symptoms of hypo/hyperglycemia. There were no dysmorphic feature. She is developmentally up to her age.

Treatment transfer 
Mutation analysis of the KCNJ11, ABCC8 and INS genes has been undertaken for the child and her parents, who were clinically unaffected. Result showed that the child is heterozygous for the p.E227K missense mutation in the KCNJ11 gene. This result confirms a diagnosis of diabetes due to a mutation in the Kir6.2 subunit of the KATP channel. While none of the parents has The KCNJ11 gene mutation p.E227K. Shrook is therefore unlikely to have inherited this mutation from her parent, it is therefore likely that the p.E227K mutation has arisen de novo.

It was explained to the parents that other people with KCNJ11 PND had successfully undergone treatment transfer from insulin injections to sulphonylurea tablets. They agreed, and she was admitted electively to the hospital for the conversion.

Before treatment transfer, C-peptide level fasting and post prandial with blood glucose level was taken respectively

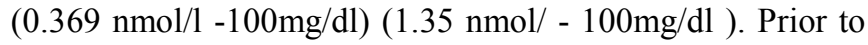
conversion, the child had been taking intermediate insulin 4 units pre-breakfast and 5 units pre-dinner time. At this time, her weight was $17.14 \mathrm{~kg}$ on the on the $10^{\text {th }}$ percentile ) her height was $105 \mathrm{~cm}$ just below the $5^{\text {th }}$ percentile. And her $\mathrm{HbA}_{1 \mathrm{c}}$ level was $7.14 \%(128.5 \mathrm{mmol} / \mathrm{mol})$. As her blood glucose levels were well controlled, glibenclamide $2 \mathrm{mg} /$ day $(0.05 \mathrm{mg} / \mathrm{kg} / \mathrm{day})$ divided on two doses was initially added to her insulin doses which were reduced to intermediate insulin 2 units pre-breakfast and 3 units pre-dinner time unit

Three days later, further reduction of insulin doses was mad; pre-breakfast 1 units and 2 units pre-dinner time. As the pre-meals blood glucose levels were within the normal level, more to the lower side. The insulin dose became one unit pre-breakfast and one unit pre-dinner time units for one day. Then it became one unit per day at morning time for another day, then it discontinued completely.

Patient was discharge on glibenclamide $1 \mathrm{mg}$ PO BID, to follow up her pre-meal glucose levels in the clinic .

\section{Discussion}

A rare form of monogenic diabetes is the neonatal diabetes (6) ,which is diagnosed within the first 6 months of life $(7,8)$. Neonatal diabetes is reportedly affecting 1 in 400,000 infants worldwide (7). $50 \%$ of the patients, the diabetes is transient (TNDM; MIM\#601410), resolving within 3 months, and 50\% of the patients have a permanent form of diabetes (PNDM; MIM\# 606176) (9). In this type of diabetes, auto antibodies are rare and human leukocyte antigen (HLA) genotyping reveals HLA haplotypes actually protective for type 1 diabetes mellitus (7).

The majority of cases with neonatal diabetes mellitus were caused by a mutation in the heterozygous or homozygous state in one of possible genes (9). Mutations in the KCNJ11 (MIM\# 600937), and ABCC8 (MIM\# 600509) genes encoding the two protein subunits (kir6.2 and SUR1) of the ATP-sensitive potassium channel are the most common causes of both permanent and transient neonatal diabetes mellitus $(7,9)$. Other genetic causes of PNDM are mutation in the insulin promoter factor-1, forehead box-P3 and glucokinase (9). Permanent neonatal diabetes requires lifelong therapy of insulin while transient neonatal diabetes remits early, with a possible relapse during adolescence (9).

Monogenic diabetes results from the inheritance of a mutation or mutations in a single gene. The mode of inheritance may be dominant or recessive or may be a de novo mutation and hence a spontaneous case (10). As in our case it is most probably to be de novo in origin since the genetic study sowed that none of the parent has the gene.

Most patients with permanent neonatal diabetes mellitus have mutations that affect the ATP-sensitive potassium channel (KATP channel), which regulates the release of insulin from pancreatic beta cells. Activating mutations increase the number of open KATP channels at the plasma membrane, hyperpolarizing the beta cells, and preventing the release of insulin.

Mutations in the KCNJ11 gene encoding the Kir6.2 subunit of the beta-cell adenosine triphosphate (ATP)sensitive potassium $\left(\mathrm{K}_{\mathrm{ATP}}\right)$ channel are the most common genetic cause of permanent neonatal diabetes (10).

Mutations in the KCNJ11 gene inhibit $\mathrm{K}_{\mathrm{ATP}}$-channel closure in response to increased levels of ATP, thereby preventing membrane depolarisation and insulin secretion. Treatment with sulphonylureas, which bind to the SUR1 receptor of the $\mathrm{K}_{\mathrm{ATP}}$ channel, allows insulin to be released from the pancreatic beta-cell (11). Therefore, many people with neonatal diabetes who have previously been dependent on insulin can now be successfully treated with sulphonylureas (12). Any SU can be as effective as any other in treating the diabetes. Gliclazide only binds to SUR1 (pancreas/neurons) whereas Glibenclamide binds to cardiac and muscle (SUR2A) as well. We used glibenclamide in our case but other sulphonylureas have been successfully used (2).

Our patient changed treatment from insulin to glibenclamide usinglan inpatient-based short transfer protocol (2), before therapy change, the patient had an insulin requirement of $0.9 \mathrm{U} / \mathrm{kg} / \mathrm{d}$. Insulin was reduced during the first day of SU substitution to less than $20 \%$ of its pre-transfer dose and then used only as a bolus for hyperglycemia correction .

There are some remarkable benefits of SU treatment. This includes improved glycemic control and the flexibility to respond with appropriate insulin secretion, which is very important for a normal lifestyle. In addition, The commonest known side effects of SU are: skin allergies (1-5\%) which may resolve and gastrointestinal including diarrhoea (1-2\%). Blood disorders - anaemia, leucopoenia and thrombocytopenia - are rare. Sulfonylureas can occasionally cause a disturbance in liver function and these are only mild and transitory (2).

\section{Conclusion}

Recognition of permanent neonatal diabetes is important as the majority of patients with a KATP-channel mutation 
can successfully undergo treatment transfer from insulin to sulphonylureas which may be attempted at any age, even after many years of receiving insulin injections

\section{Acknowledgment}

We thank Prof. Sian Ellard, Consultant, Molecular Genetics Laboratory, Royal Devon and Exeter NHS Healthcare Trust, Barrack Road, Exeter, United Kingdom, Andrew Parrish, Genetic Technologist, and Jayne Houghton, Clinical Scientist, for their excellent assistance and support in accomplishing this work

\section{References}

[1] Karl Ernst von Mühlendah, M.D., and Heiner Herkenhoff, M.D. Long-Term Course of Neonatal Diabetes .N Engl J Med 1995; 333:704-708 DOI: 10.1056/NEJM199509143331105

[2] Gloyn AL, Pearson ER, Antcliff JF, Proks P, Bruining GJ, Slingerland AS, Howard N, Srinivasan S, Silva JM, Molnes J, Edghill EL, Frayling TM, Temple IK, Mackay D, Shield JP, Sumnik Z, van Rhijn A, Wales JK, Clark P, Gorman S, Aisenberg J, Ellard S, Njølstad PR, Ashcroft FM, Hattersley AT. Activating mutations in the gene encoding the ATPsensitive potassium-channel subunit Kir6.2 and permanent neonatal diabetes. N Engl J Med. 2004;350(18):1838.

[3] Gloyn AL, Cummings EA, Edghill EL, Harries LW, Scott R, Costa T, Temple IK, Hattersley AT, Ellard S. Permanent neonatal diabetes due to paternal germline mosaicism for an activating mutation of the KCNJ11 Gene encoding the Kir6.2 subunit of the beta-cell potassium adenosine triphosphate channel. J Clin Endocrinol Metab. 2004;89(8):3932

[4] Pearson ER, Flechtner I, Njølstad PR, Malecki MT, Flanagan SE, Larkin B, Ashcroft FM, Klimes I, Codner E, Iotova V, Slingerland AS, Shield J, Robert JJ, Holst JJ, Clark PM, Ellard S, Søvik O, Polak M, Hattersley AT, Neonatal Diabetes International Collaborative Group . Switching from insulin to oral sulfonylureas in patients with diabetes due to Kir6.2 mutations.N Engl J Med. 2006;355(5):467.

[5] Landau Z, Wainstein J, Hanukoglu A, Tuval M, Lavie J, Glaser B. Sulfonylurea-responsive diabetes in childhood. J Pediatr. 2007;150(5):553
[6] Zung A, Glaser B, Nimri R, Zadik Z. Glibenclamide treatment in permanent neonatal diabetes mellitus due to an activating mutation in Kir6.2 . J Clin Endocrinol Metab. 2004 Nov;89(11):5504-7

[7] Hattersley AT, Ashcroft FM. Activating mutations in Kir6.2 and neonatal diabetes: new clinical syndromes, new scientific insights, and new therapy. Diabetes, VOL. 54, september 2005. ADA.

[8] Anna L. Gloyn, D.Phil., Ewan R. Pearson, M.R.C.P., Jennifer F. Antcliff, B.Sc., Peter Proks, D.Phil., G. Jan Bruining, M.D., Annabelle S. Slingerland, M.D., Neville Howard, M.D., F.R.A.C.P., Shubha Srinivasan, M.B., B.S., M.R.C.P., José M.C.L. Silva, M.D., Janne Molnes, M.Sc., Emma L. Edghill, M.Sc., Timothy M. Frayling, Ph.D., I. Karen Temple, F.R.C.P., Deborah Mackay, Ph.D., Julian P.H. Shield, M.D., F.R.C.P.C.H., Zdenek Sumnik, M.D., Adrian van Rhijn, M.D., Jerry K.H. Wales, D.M., F.R.C.P.C.H., Penelope Clark, Ph.D., F. R. C. Path., Shaun Gorman, M.R.C.P., Javier Aisenberg, M.D., Sian Ellard, Ph.D., M. R. C. Path., Pål R. Njølstad, M.D., Ph.D., Frances M. Ashcroft, Ph.D., and Andrew T. Hattersley, D.M., F.R.C.P. Activating Mutations in the Gene Encoding the ATP-Sensitive Potassium-Channel Subunit Kir6.2 and Permanent Neonatal Diabetes .N Engl J Med 2004;350:1838-49.

[9] Rica I, Luuriaga C, Peres de Nanclares G, Estalella I, Aragones A, et al.The majority of cases of neonatal diabetes in Spain can be explained by known genetic abnormalities. DIABETIC Medicine 2007; 24:707-13.

[10] 10.Slingerland AS, Nuboer R, Hadders-Algra M et al (2006) Improved motor development and good longterm glycaemic control with sulfonylurea treatment in a patient with the syndrome of intermediate developmental delay, early-onset generalised epilepsy and neonatal diabetes associated with the V59M mutation in the KCNJ11 gene. Diabetologia 49: 255963

[11] Edghill et al, Insulin Mutation Screening in 1,044 Patients With Diabetes .Mutations in the INS Gene Are a Common Cause of Neonatal Diabetes but a Rare Cause of Diabetes Diagnosed in Childhood or Adulthood. DIABETES, VOL. 57, APRIL 2008

[12] Sagen JV, Ræder H, Hathout E et al (2004) Permanent neonatal diabetes due to mutation in KCNJ11 encoding Kir6.2: patient characteristics and initial response to sulfonylurea therapy. Diabetes 53: 2713-18 